\title{
Use of toenail-bounded heavy metals to characterize occupational exposure and oxidative stress in workers of waterpipe/cigarette cafés
}

\author{
Mohammad Reza Masjedi • Sina Dobaradaran • Saeed Keshmiri • \\ Farhad Taghizadeh - Hossein Arfaeinia - Farzad Fanaei - Mojtaba Behroozi • \\ Farzaneh Nasrzadeh • Melika Joukar
}

Received: 11 June 2020/ Accepted: 9 October 2020

(C) Springer Nature B.V. 2020

\begin{abstract}
Tobacco smoke is known for releasing metals in indoor air of waterpipe/cigarette cafés. However, the worker exposure to metals, and its association with oxidative stress in these cafés are still unclear. To this end, 54 workers and 38 customers from waterpipe/cigarette cafés (the exposed group), 30 workers from non-smoking cafés (the control group 1 (CG_1)) and 32 individuals from the general population (the control group 2 (CG_2)) were selected and toenails samples were then taken from them. Our findings revealed a significant difference in terms of toenail-bounded metal levels between the exposure and control groups (CG_1 and CG_2) (Mann-Whitney $U$ test, $\left.P_{\text {value }}<0.05\right)$. This study has also indicated that "type of tobacco" could be considered as a predictor for toenail-bounded heavy metals.
\end{abstract}

M. R. Masjedi

Tobacco Control Research Center (TCRC), Iranian Anti-

Tobacco Association, Tehran, Iran

S. Dobaradaran · S. Keshmiri · H. Arfaeinia .

M. Behroozi · F. Nasrzadeh · M. Joukar

Systems Environmental Health and Energy Research

Center, The Persian Gulf Biomedical Sciences Research

Institute, Bushehr University of Medical Sciences,

Bushehr, Iran

S. Dobaradaran · H. Arfaeinia ( $\square)$

Department of Environmental Health Engineering, Faculty of Health and Nutrition, Bushehr University of Medical Sciences, Bushehr, Iran

e-mail: arfaeiniah@yahoo.com
Furthermore, our research's results suggest that toenail-bounded heavy metals are positively and significantly correlated with urinary levels of 8- hydroxy-2'deoxyguanosine $(8-\mathrm{OHdG}$, as a biomarker for the degradation of deoxyribonucleic acid (DNA) oxidative stress). Therefore, it can be concluded that workers of waterpipe/cigarette cafés are at high risks of adverse health of DNA oxidative degradation.

Keywords Smoking - Waterpipe $\cdot$ Cigarette $\cdot$ Heavy metal $\cdot$ Toenail $\cdot$ DNA oxidative stress

\author{
S. Keshmiri \\ Faculty of Medicine, Bushehr University of Medical \\ Sciences, Bushehr, Iran \\ F. Taghizadeh $\cdot$ F. Fanaei \\ Department of Environmental Health Engineering, \\ Faculty of Health, Iran University of Medical Sciences, \\ Tehran, Iran
}




\section{Introduction}

In recent years, the consumption of waterpipe and cigarette has become more prevalent among teenager and young people in recent years (Asfar et al. 2005). In this regard, the use of waterpipe, as a wrong entertainment, had been prevalent for a long time in the Middle East, the Mediterranean, some SouthAmerican countries, and some Asian countries, including Iran, and it causes about 6 million (annually) deaths worldwide (WHO 2017). The health effects of tobacco are resulted from the interaction of the body with the hazardous and toxic substances found in tobacco smoke, which subsequently enter the human body through repeated puffs (Drago et al. 2018; Masjedi et al. 2019a). Tobacco smoke contains thousands of harmful and hazardous chemicals released into the air of cafés in the form of gaseous and particulate matter (Heydari et al. 2019; Rodgman and Perfetti 2016). Many scientific studies have focused on heavy metals present in the particle phase of the present species of cigarette smoke (Verma et al. 2010; Lugon-Moulin et al. 2004). Accordingly, it has been reported that various metals such as arsenic (As), lead $(\mathrm{Pb})$, cadmium $(\mathrm{Cd})$, manganese $(\mathrm{Mn})$, and zinc (Zn) with considerable concentrations exist in tobacco smoke (Swami et al. 2009). Fromme et al. (Fromme et al. 2009) in their study have reported significant levels of carcinogenic metals such as lead $(11.2 \mathrm{ng} /$ $\left.\mathrm{m}^{3}\right)$, cadmium $\left(0.38 \mathrm{ng} / \mathrm{m}^{3}\right)$, and thallium $(1.14 \mathrm{ng} /$ $\mathrm{m}^{3}$ ) in the indoor air inside of smoking cafés. As mentioned earlier, one of the major pollutants in tobacco smoke considered to be heavy metals whose its health effects have been well-documented. Accordingly, it was shown that the severity of these effects largely depends on the chemical state of the heavy metals (inorganic or organic), the metal's concentration, the contact time (duration of exposure), and the age of the smokers (Asante et al. 2012; Jafari et al. 2018; Haghnazari et al. 2018). Some heavy metals such as $\mathrm{As}, \mathrm{Pb}, \mathrm{Cd}, \mathrm{Ni}, \mathrm{Cr}, \mathrm{Co}$, and Hgare toxic elements that can cause several problems such as DNA damage, disruption of the hormonal balance, stimulation of the respiratory system, the decreased blood pressure, complications of the central nervous system, anemia, the decreasedintelligence quotient (IQ), the decreased physical and mental growth of children, the reduction of sperm production, leading to a disorder in activity of sperm'senzymes. Moreover, they can also cause some symptoms such as headaches, dizziness, abdominal pain, irritation, and skin ulcers (GhezelAhmadi et al. 2010; Habibollahi et al. 2019). In addition, some heavy metals can be accumulated in the body, which consequently leads to damage to the kidneys and bone structure in case of a long time exposure of someone to tobacco smoke (Liu et al. 2020). Furthermore, they can cause cancer in the longtime exposure as well (Lim et al. 2019). Thus, human health might be threatened by metal exposure. In this regard, it is noteworthy that, the mechanism of metalinduced human diseases possibly involves oxidative stress (Zhang et al. 2019). Several animal and in vitro studies have revealed that redox active metals, such as $\mathrm{Cu}, \mathrm{Cr}, \mathrm{Co}$, and other metals, undergo redox cycling reactions and produce reactive oxygen species (ROS), which overwhelms body antioxidant protection and subsequently induce DNA damage (Ni et al. 2014). Thus, it can be concluded that workers in tobacco cafés (waterpipe and cigarettes) are an important occupational group who are potentially exposed to heavy metals. However, there is no available data on the association between human metal exposure and DNA damage in these cafés.

Biomonitoring, as an appropriate approach, is widely used to assess occupational and environmental exposure to various pollutants (Yang et al. 2019; Camargo et al. 2019). In this regard, performing biological monitoring of heavy metals in different biological samples (such as nails, blood plasma, urine, and saliva) can indicate the exposure to heavy metals (Al-Saleh 2020; Camargo et al. 2019). It is noteworthy that the shelf-life of heavy metals in blood and urine is between 2 and $3 \mathrm{~h}$ and between 3 and 4 days, respectively. So, they can be considered them more suitable samples for assessing the acute exposure, while nails with a growth rate of 0.05 to $1.2 \mathrm{~mm} /$ week reflect a longer-term exposure (Ab Razak et al. 2015). Moreover, nails have many advantages such as noninvasive collection, easier collection and transportation, a higher stability at room temperature, and relatively higher concentrations of elements (metals) compared to the other biological specimens (such as blood, urine, sweat and other available tissues) ( $\mathrm{Li}$ et al. 2012; Samanta et al. 2004). In addition, metals bounded to the nails are not exposed to the additional metabolic processes and many metals in considerably higher levels exist in the nail compared to blood plasma or urine samples (Hordinsky et al. 2000). 
Toenails have less growth rate than finger-nails, which they also are less exposed to external contamination (Karatela et al. 2018). Therefore, toenail samples can represent the integrated heavy metal exposure over the past 2 to 12 months before the clipping (Karatela et al. 2018). So, the level of contaminants in toenails can be used as an indicator for monitoring as well as evaluating a long-term exposure to heavy metals in different occupational groups (Wongsasuluk et al. 2018).

However, to the best of our knowledge, no studies have been conducted on investigating heavy metals in toenails of people working in waterpipe/cigarette cafés so far, in order to evaluate their exposure to heavy metals. Therefore, for the first time, this study was conducted to evaluate the exposure of waterpipe/cigarette cafés' employees to heavy metal by measuring the heavy metals in their toenails samples. Furthermore, the effects of lifestyle and occupational factors such as age, sex, body mass index (BMI), the use of tobacco, type of tobacco consumed, work time duration in cafe's, cafés distance from traffic, and the use of protective equipment were evaluated in the present study as well. Finally, urinary level of 8hydroxy-2'-deoxyguanosine (8-OHdG) was used as a biomarker to evaluate the association between workers' metal exposure and degradation of DNA oxidative stress.

\section{Materials and methods}

Research design and sampling sites' selection

In this study, smoking cafés in Bushehr city, Iran were firstly reviewed and then listed. Afterward, 54 smoking cafés (of 83 available smoking cafés) were randomly chosen. To this end, smoking cafés were first coded from 1 to 83 , and then 54 out of 83 cafés were randomly selected through formulation in Excel using the following randomization function (Eq. 1).

$0 \leq 83 \times$ Rand ()$\leq 83$

Thereafter, addresses and other information of the selected cafés were provided for performing sampling. 34 out of 54 cafés were waterpipe cafés (hereafter referred to as WPC), and 20 ones were cigarette cafés (hereafter referred to as CC). One employee was selected from each café (totally 54 employee) and 38 subjects were selected from customers of these tobacco cafés. In addition, 30 non-smoking cafés were selected as the control group 1 (hereafter referred to as CG_1). Besides, a café worker and a customer were selected from each café; and toenail (all ten toes) samples were then taken from them.

Furthermore, 32 individuals from the general population were considered as the control group 2 (hereafter referred to as CG_2), and toenails samples were collected from them. It is noteworthy that people with any illness or disorder were excluded from the study to prevent its possible impact on the results. In this regard, all participants were healthy. After this step, the selected cafés were visited and then the necessary explanations were given to the cafés owners, managers, workers and customers to convince them, in order to obtain the sampling permit. Moreover, the smoking customers were aware that measurements would take place in indoor air of those cafés. It should be noted that this research was performed in terms of the ethical principles of Research Ethics Committee of Iran (IR.BPUMS.REC.1399.012). The sampling operation began after convincing them as well as collecting informed consent forms.

\section{Data collection and sampling}

Prior to sampling, the background information of each café, such as the type of supplied tobacco (fruit flavored or traditional tobacco) and the cafés distance from traffic were recorded using the pre-designed checklist. In addition, sample donor information such as age, gender, height, weight, BMI, educational level, the use of tobacco, employment period, and the use of personal protective equipment were also recorded. The information on each café and each one of the studied people are given in Table 1. After performing this step, the included participants were taught about how to collect the samples correctly and the best way to prevent possible contamination was shown them. Therefore, a sample pack containing a disposable stainless steel razors and a polyethylene bag was given to the participants to ensure uniformity during sampling. The studied participants were then asked to wash their feet and toes with water and soap and to dry them with clean towels. Subsequently, they were asked to remove their toenails with a razors and to pack them in clean polyethylene bags. The samples 
Table 1 General characteristics of participants

\begin{tabular}{|c|c|c|c|c|}
\hline \multirow{2}{*}{$\begin{array}{l}\text { Characteristics } \\
\text { Subjects number }\end{array}$} & \multicolumn{2}{|l|}{ Exposed group } & \multirow{2}{*}{$\begin{array}{l}\text { Control Group } 1 \\
30.0\end{array}$} & \multirow{2}{*}{$\frac{\text { Control Group } 2}{32.0}$} \\
\hline & Employee (54.0) & Costumer (38.0) & & \\
\hline Gender & Male $(100 \%)$ & Male $(100 \%)$ & Male $(100 \%)$ & Male $(100 \%)$ \\
\hline Age (year) & $34.0 \pm 2.44$ & $35.0 \pm 2.29$ & $32.0 \pm 3.06$ & $35.0 \pm 2.56$ \\
\hline Height $(\mathrm{cm})$ & $174 \pm 4.12$ & $178 \pm 7.61$ & $174 \pm 6.43$ & $176 \pm 5.32$ \\
\hline Weight (kg) & $80.0 \pm 7.87$ & $79.0 \pm 5.88$ & $81.0 \pm 6.45$ & $79.0 \pm 9.12$ \\
\hline BMI $\left(\mathrm{kg} / \mathrm{m}^{2}\right)$ & $26.3 \pm 1.09$ & $26.4 \pm 1.41$ & $27.1 \pm 1.12$ & $25.5 \pm 1.17$ \\
\hline \multicolumn{5}{|l|}{ Education level (\%) } \\
\hline Illiterate/can only read and write & 27.0 & 15.4 & 11.8 & - \\
\hline Up to 10 years of schooling & 59.5 & 57.7 & 64.7 & 40.0 \\
\hline More than 10 years of schooling & 13.5 & 26.9 & 23.5 & 60.0 \\
\hline Employment period (month) & $29.7 \pm 8.6$ & - & $37.3 \pm 46.7$ & - \\
\hline \multicolumn{5}{|l|}{ Tobacco type $(\%)^{\mathrm{a}}$} \\
\hline Fruit flavored & 29.7 & 34.4 & - & - \\
\hline Traditional & 24.3 & 25.0 & - & - \\
\hline Cigarette & 29.7 & 25.0 & - & - \\
\hline None & 16.2 & 15.6 & - & - \\
\hline \multicolumn{5}{|c|}{ Traffic near the residence location $(\%)^{\mathrm{b}}$} \\
\hline Heavy & 54.3 & 26.9 & 41.2 & 20.0 \\
\hline Moderate & 25.7 & 53.8 & 29.4 & 35.0 \\
\hline Light & 20.0 & 19.2 & 29.4 & 45.0 \\
\hline \multicolumn{5}{|l|}{ Personal protective equipment (\%) } \\
\hline No & 81.1 & - & 00.0 & - \\
\hline Occasionally & 13.5 & - & 23.5 & - \\
\hline Yes (full-time) & 5.40 & - & 76.5 & - \\
\hline
\end{tabular}

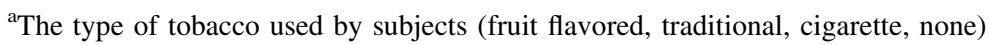

${ }^{\mathrm{b}}$ Traffic density in the district of each café

obtained from the control groups 1 and 2 were sampled in the same way. Moreover, customers of cafés were randomly sampled (their samples were also collected and then prepared as described earlier). Afterward, the collected toenails samples were immediately labeled, coded, and transferred to the laboratory. In the laboratory, the samples were packed appropriately and kept at room temperature for chemical analysis.

Sampler of this study had learned the necessary training to "transfer biological samples" and had extensive experience in appropriate handling (sampling, packaging and transporting) of biological samples such as urine, nails, and blood.
Preparation and analysis of nail samples

At this stage, the samples were thoroughly washed to remove any external contamination (Ndilila et al. 2014). The used method to clean the outer surface of the toenails was based on the published paper by Mehra et al. (Mehra and Juneja 2005). The toenail samples were then autoclaved for $45 \mathrm{~min}$ to eliminate any microbial contamination. Afterward, these samples were placed in Milli-Q water for $30 \mathrm{~min}$ in ultrasonic. Acetone was then replaced with Milli-Q water and it was again placed in ultrasonic for another $30 \mathrm{~min}$, to remove any organic contamination (Ndilila et al. 2014). Next, the toenails were rinsed 5 times with Milli-Q water and then dried at oven for 60 min until their weight became a fixed. Thereafter, these dried toenails samples were digested using wet acid 
digestion method (4 $\mathrm{ml}$ concentrated nitric acid) at $65{ }^{\circ} \mathrm{C}$ for $2 \mathrm{~h}$. Then, $4 \mathrm{ml}$ of hydrogen peroxide was added to the samples and held at $65^{\circ} \mathrm{C}$ until the time that reaction was complete. After preparing the samples, a quadrupole Inductively Coupled Plasma Atomic Emission Spectroscopy (ICP) equipped with Mass Spectrometry (MS) (ICP-MS, Elan 5000, Perkin Elmer) apparatus was used to quantify the concentration of 8 heavy metals including $\mathrm{Pb}, \mathrm{Cd}, \mathrm{Co}, \mathrm{As}, \mathrm{Cr}$, $\mathrm{Ni}, \mathrm{Zn}$ and $\mathrm{Cu}$. The parameters for ICP-MS are as follows: forward power of $1000 \mathrm{~W}$, nebulizer gas flow rate of $0.8 \mathrm{~L} / \mathrm{min}$, sample injection mode: manual mode, integration time: $5 \mathrm{~s}$, and sampling depth: $10 \mathrm{~mm}$.

For quality control and quality assurance (QC/QA), parallel to the samples preparations, the blank samples were also extracted with a similar procedure without toenail samples. Multi-element standard solution was purchased from Merck (Darmstadt, Germany) and utilized for preparation on calibration standards. Moreover, the equipment was calibrated on a daily basis by calibration standards. A spiked blank, method blank and matrix spike, as well as replication of the samples were performed for each batch of the samples. All samples were analyzed in triplicate to demonstrate reproducibility of the equipment. The relative deviation of the replicate samples was within $\pm 5 \%$ in all batch runs. The extent of recovery for the 8 metals in the spiked blank samples was obtained within the range of $76.4-113 \%$ with a standard deviation of $<$ $10 \%$. Further, in the samples, for 8 metals in matrix spike samples, it was achieved within the range of $80.41-111 \%$ with a standard deviation of about $10.3 \%$. Very little levels of some elements were seen in the method blank samples, which were suitably subtracted from the values read in the samples. The correlation coefficients $\left(\mathrm{R}^{2}\right)$ and linear ranges were 0.1-99.97 ng/mL and 0.9995 for $\mathrm{Zn}, 0.1-19.97 \mathrm{ng} /$ $\mathrm{mL}$ and 0.9994 for $\mathrm{Cu}, 0.1-9.77 \mathrm{ng} / \mathrm{mL}$ and 0.9983 for $\mathrm{Pb}, 0.1-9.74 \mathrm{ng} / \mathrm{mL}$ and 0.9974 for Cd, 0.5-10.17 ng/ $\mathrm{mL}$ and 0.9994 for As, $0.1-9.73 \mathrm{ng} / \mathrm{mL}$ and 0.9963 for Co, $0.1-9.97 \mathrm{ng} / \mathrm{mL}$ and 0.9998 for $\mathrm{Cr}$, and 0.1-9.69 ng/mL and 0.9967 for Ni. Correlation coefficients $\left(\mathrm{R}^{2}\right)$ ranging from 0.9963 to 0.9998 indicated good linearity for all metals. The method limits of detection (LODs) were $0.017 \mu \mathrm{g} / \mathrm{g}$ for $\mathrm{Zn}, 0.011 \mu \mathrm{g} / \mathrm{g}$ for $\mathrm{Cu}, 0.006 \mu \mathrm{g} / \mathrm{g}$ for $\mathrm{Pb}, 0.009 \mu \mathrm{g} / \mathrm{g}$ for $\mathrm{Cd}$, $0.014 \mu \mathrm{g} / \mathrm{g}$ for As, $0.007 \mu \mathrm{g} / \mathrm{g}$ for Co, $0.017 \mu \mathrm{g} / \mathrm{g}$ for $\mathrm{Cr}$, and $0.018 \mu \mathrm{g} / \mathrm{g}$ for $\mathrm{Ni}$.
Analysis urinary 8-OHdG

A subset of 134 urine samples collected from waterpipe/cigarette cafés (54 workers and 38 customers), the control group $1(n=30)$ and control group 2 $(n=32)$ were analyzed using the 8 -OHdG Check ELISA kit (Japan Institute for the Control of Aging, Nikken SEILCo., Shizuoka, Japan) for 8-hydroxydeoxyguanosine $(\mathrm{OHdG})$, which is a product of oxidative DNA damage formed by hydroxyl radicals. The coefficient of variation $(\mathrm{CV})$ and the recovery rates of $8-\mathrm{OHdG}$ was ranged from 7.21 to $8.47 \%$ and $94.0-113 \%$, respectively. Details regarding the sample preparation and analysis of $8-\mathrm{OHdG}$ are described elsewhere (Bamai et al. 2019).

\section{Statistical analyses}

Statistical analyses of the current research were performed using Microsoft Excel 2016 and SPSS (version 21.0; SPSS Inc.). The latest version of $\mathrm{R}$ software ( $\mathrm{R}$ 4.0.2 for Windows) was utilized to prepare the box and whisker plot. Moreover, Shapiro-Wilk test was used to evaluate the data distribution normality for each of the variables. Difference between toenail metals levels between exposed and control groups were examined by Mann-Whitney $U$ nonparametric test. Since the data distribution of metals was not normal, so the metal concentrations were analyzed by the log-transform multiple linear regression analysis. Accordingly, this analysis was done by the association between concentrations of metals and independent variables, including age, BMI, tobacco use, type of tobacco (fruit-flavored tobacco, traditional tobacco, and cigarette), distance from traffic, length of time spent in the cafés, and use of personal protective equipment. $P_{\text {value }}<0.05$ was considered as the statistical significant level and all $P_{\text {value }}$ in this research were two-sided.

\section{Results and discussion}

Demographic and lifestyle characteristics of participants

In this study, a group of 92 individuals (54 workers and 38 customers) from smoking cafés were considered as an exposed group. Two non-exposed groups, 
including 30 non-smoking cafés workers (the control group 1 (GC_1)) and 32 subject from general populations (control group 2 (GC_2)) were selected. The demographic and lifestyle characteristics of these research subjects are presented in Table1 (based on the checklists' information). As shown, all the subjects were male with the mean age of $34,35,32$, and 35 years in smoking cafés workers, customers, GC_1, and GC_2, respectively. The participants in GC_1 were slightly younger than the other two groups. There was no significant difference in terms of weight, height and BMI between the exposed and the control groups. According to the WHO classification, most of the subjects were in slightly overweight $(58 \%)$ and normal weight $(33 \%)$ classes; and $9 \%$ of participants were overweight. Moreover, most of the individuals of the exposed group had low socioeconomic and educational status. Notably, there was a significant difference (Mann-Whitney $U$ test, $P$ value $<0.05$ ) in employment periods between smoking cafés workers and $\mathrm{CG}_{-} 1$ group, in a way that non-smoking cafés workers (CG_1) had a longer employment duration. Most of these subjects used fruit-flavored tobacco. Unfortunately, a few people in the smoking cafés used personal protective equipment (about 5\%).

Toenail metals concentrations in exposure/control groups

Toenails are considered as one of the body tissues, in which many intaked metals are accumulated. In addition, toenails metal levels could be used as a biological index to reflect the recent exposure (recent several days-weeks) (Ab Razak et al. 2015). In this study, the concentrations of 8 heavy metals (lead, cadmium, arsenic, nickel, chromium, cobalt, copper and zinc) were examined in the toenail samples collected from the exposed groups (including waterpipe/cigarette cafés workers and customers) and the two control groups (CG_1 and $\left.C G \_2\right)$.In this regard, the statistical results are presented in Fig. 1 and Table 2. Except $\mathrm{As}, \mathrm{Pb}, \mathrm{Cd}$ and $\mathrm{Ni}$ in the two control groups (CG_1 and $\left.C G \_2\right)$, the rest of metals were detected (>LOQ) in all 154 samples. The mean concentration of $\sum$ heavy metal in the toenailsamples obtained from waterpipe cafés and cigarette cafés workers were 5.31 and 4.67 times higher than the CG_1 samples and 8.39 and 7.37 times higher than the CG_2 samples, respectively. Thus, it can be strongly

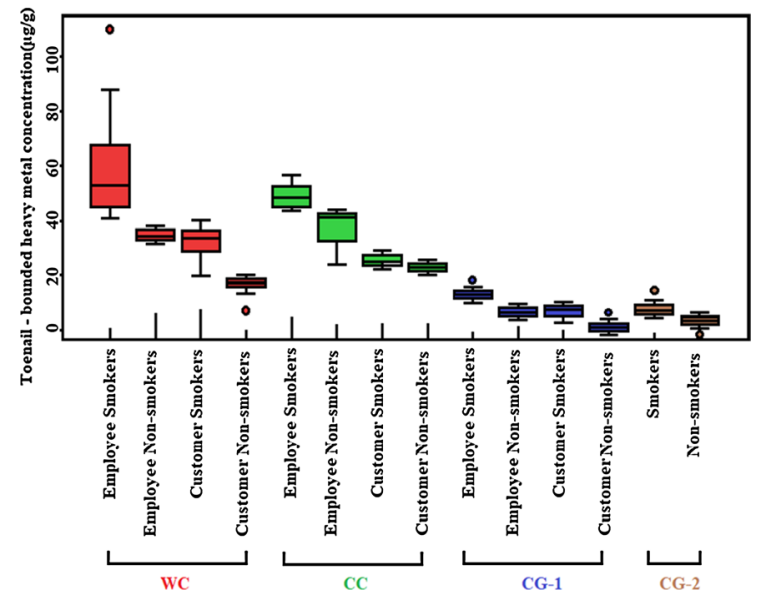

Fig. 1 Box plot of levels of toenail-bounded heavy metals ( $\mu \mathrm{g} /$ $\mathrm{g}$ ) in exposed and control groups (employee: workers in waterpipe/cigarette cafés, Customers: customers in waterpipe/cigarette cafés, CC: cigarette cafés, WC: waterpipe cafés, CG-1: control group 1 and CG-1: control group 2) (in this box plot $\mathrm{a}, \mathrm{b}, \mathrm{c}, \mathrm{d}$, e and $\mathrm{f}$ are outliers, maximums, upper quartiles, medianss, upper quartiles and minimums, respectively)

stated that working in smoking cafés was a considerable source of exposure to various pollutants like heavy metals (Swami et al. 2009). Moreover, it was found that the median concentrations of $\sum$ heavy metal were higher in the toenail samples collected from waterpipe/cigarette cafés workers compared to the samples obtained from the customers of these cafés. The higher concentrations of toenail metals were also observed in smoking cafés workers compared to the customers, which might be due to the fact that cafés workers usually spend much more time in cafés with a low quality air; therefore, their exposure to tobacco smoke contaminants is higher (Akl et al. 2010; Gurung et al. 2016). The findings have also indicated that the amounts of metals were higher in waterpipe cafés workers and customers compared to cigarette cafés. The findings of our previous studies have also indicated that the concentrations of emitted metals were higher by waterpipe smoking compared to cigarette (Heydari et al. 2019; Masjedi et al. 2019b). Furthermore, there was a significant difference in terms of metal levels between the toenails samples of the exposure and control groups (CG_1 and $\left.C G \_2\right)$ (Mann-Whitney $U$ test, $P$ value $<0.05$ ). Consequently, this indicates that there was a close relationship between smoking activities and a higher accumulation of metal in the toenails. Numerous 


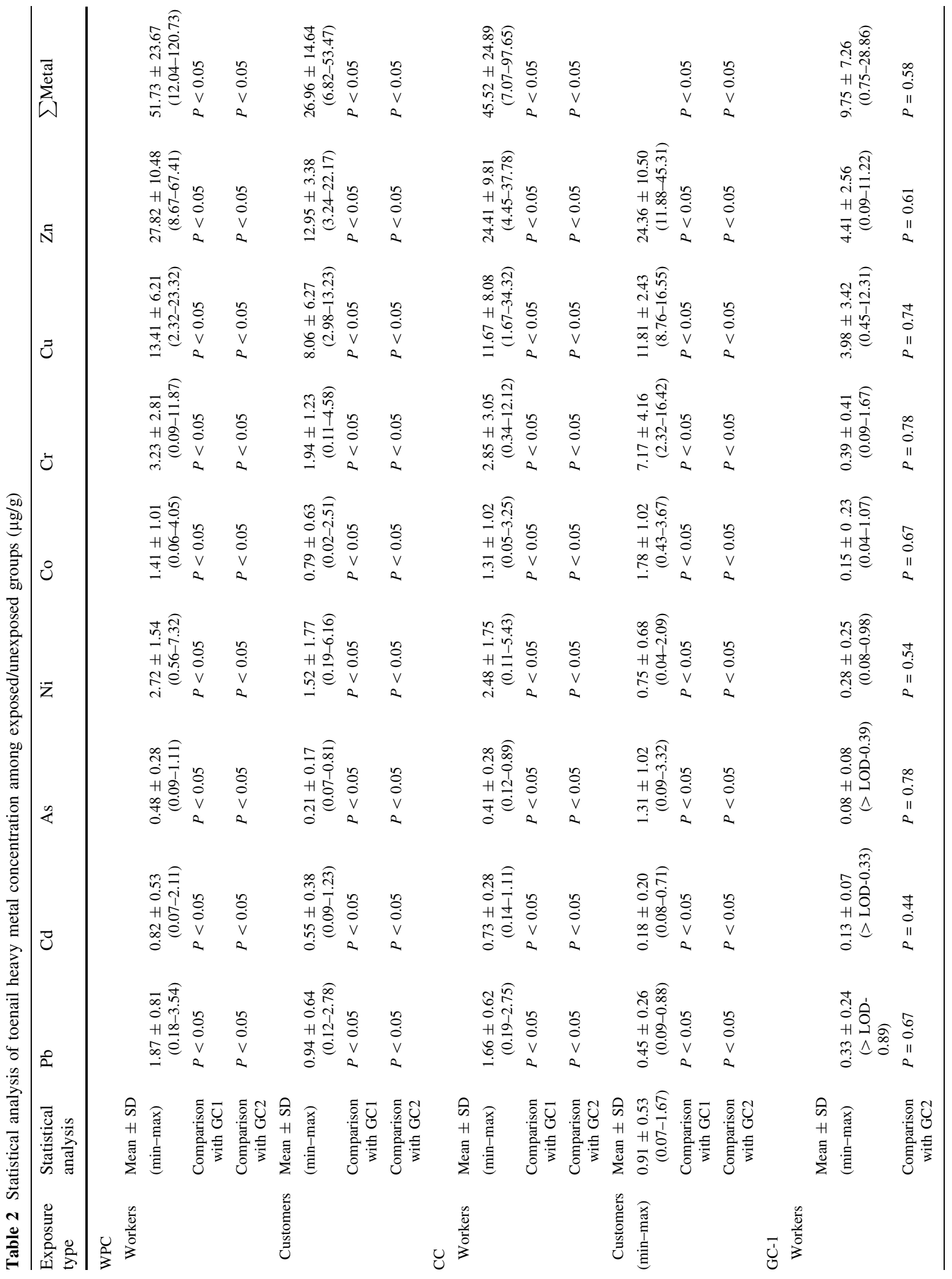


studies have found a positive association between toenails metal levels and occupational exposure (Hinwood et al. 2003; Grashow et al. 2014). In addition, for both exposed and control groups, subjects were classified into smokers and non-smokers and the concentrations of $\sum$ heavy metal were compared in smokers and non-smokers (Fig. 1.). As can be observed, the median concentrations of $\sum$ heavy metal in toenails collected from smoker subjects were higher than samples of non-smokers in all groups (WC, CC, CG_1 and $\left.C G \_2\right)(P$ value $<0.05)$. The reason for this observations can be due to the fact that smoking is one of the main contributor to the body burden of heavy metal (Kim et al. 2010). Other studies have also confirmed that the levels of heavy metals (and other toxic pollutants) is higher in biological samples of smokers than non-smokers (Gregg et al. 2013; Rocha et al. 2016). The concentration of toenail-bound metals were higher in comparison with those reported for some industrial communities in Zambia (Ndilila et al. 2014). The findings of toenail-bounded metals were also higher than the corresponding values for the occupational welding fume exposure (Grashow et al. 2014; Laohaudomchok et al. 2011) and lower than those measured in Portuguese miners (Coelho et al. 2012). Higher toenail metal levels were recorded in a research from an industrialized area with high levels of environmental exposures from air particles and dust (Slotnick et al. 2005). However, those findings might have been skewed by a small number of extremely high exposures, and were estimated using adults and children, where children tend to have higher toenail metal concentrations than adults (Wilhelm et al. 1994; Wickre et al. 2004).

Geometric mean concentrations of $\mathrm{Pb}, \mathrm{Cd}$ and $\mathrm{As}$ (three toxic metals of major public concern) in the toenails samples were $1.78,0.82$ and $0.48 \mu \mathrm{g} / \mathrm{g}$ in waterpipe cafés workers, $1.66,0.77,0.41 \mu \mathrm{g} / \mathrm{g}$ in cigarette cafés workers, and $0.33,0.13$, and $0.08 \mu \mathrm{g} / \mathrm{g}$ in non-smoking cafés workers $\left(\mathrm{CG}_{-} 1\right)$, respectively. Also, in the toenails samples from the cafés customers, geometric mean concentrations of three toxic metals ( $\mathrm{Pb}, \mathrm{Cd}$, and $\mathrm{As}$ ) were $0.94,0.55$ and $0.21 \mu \mathrm{g} / \mathrm{g}$ in waterpipe cafés customers; 0.91, 0.45, $0.18 \mu \mathrm{g} / \mathrm{g}$ in cigarette cafés customers, and $0.16,0.098$ and $0.048 \mu \mathrm{g} / \mathrm{g}$ in non-smoking cafés customers (CG_1). Furthermore, geometric mean concentrations of three toxic metals $(\mathrm{Pb}, \mathrm{Cd}$ and $\mathrm{As})$ in general population (CG_2) were measured as $0.17,0.068$ and $0.043 \mu \mathrm{g} / \mathrm{g}$, 
respectively. Therefore, it can be concluded that tobacco smoke is an important source of toxic metals in indoor air of smoking cafés. So, people exposed to this smoke would consequently receive high concentrations of heavy metals. In agreement with this conclusion, Omari et al. reported high values of $\mathrm{Pb}$ in cigarette smoke of various brands in Kenya (Omari et al. 2015). Also, in a study by Fromme et al. (2009) a significant concentrations of carcinogenic metals, such as lead $\left(11.2 \mathrm{ng} / \mathrm{m}^{3}\right)$, cadmium $\left(0.38 \mathrm{ng} / \mathrm{m}^{3}\right)$, and thallium $\left(1.14 \mathrm{ng} / \mathrm{m}^{3}\right)$ were reported in indoor air of the smoking cafés. Most of the heavy metals in tobacco smoke are originated from the tobacco leaves' burning. It is notable that tobacco is a fast-growing plant, which absorbs heavy metals present in the soil into its tissues similar to other natural trees (Pappas et al. 2007). Additionally, tobacco is a sensitive plant; therefore, it is prone to many diseases. So, the farmers must use various fertilizers, herbicides, and pesticides to protect these plants from pests (Zhao et al. 2020). These pesticides usually contain heavy metals in their structures that enter various parts of the tobacco plant, and then release through smoke while burning, and finally affect the exposed people (Sebiawu et al. 2014).

In general, given the high levels of heavy metals in the toenails of workers and customers in waterpipe/cigarette cafés, it can be claimed that these individuals are highly exposed to serious health risks. In line with this claim, some previous studies have reported an association between heavy metals exposures and a higher Peripheral Artery Disease (Arora et al. 2009); among smoking, exposure to heavy metals and pancreatic cancer (Schwartz and Reis 2000), as well as the association between smoking, exposure to heavy metals, and diabetes (Schwartz et al. 2003). Another study has also reported a relationship between smoking history and cadmium accumulation in the lung tissue (Pääkkö et al. 1989). It should be noted that the biological half-life of some metals is between 20-25 years, and they can have bioaccumulation in different parts of the smokers' body due to having a high biological half-life (Suwazono et al. 2009). People with a wide age range were present in these cafés. However, active smokers were generally young men and women who spent their leisure time with their friends and waterpipe smoke. In some cases, it was also observed that children and women were also present in these cafés. Therefore, raising the awareness of women and notification about consumption of tobacco products is essential. It is also suggested that kindergartens and children schools consider some training about the harms of waterpipe and tobacco to children and students.

Effect of lifestyle and occupational factors

The multiple regression analysis (MLR) was used to evaluate the association between the measured toenail-bounded metals with influential occupational and lifestyle variables, and the results are provided in Table 3. In this analysis, the correlation between metals concentration with these factors was evaluated based on the regression coefficient ( $\beta$ coefficient) and $P$ value. As can be seen, type of tobacco, number of services per day, café's distance from traffic, and the use of personal protective equipment were identified as the predictors of toenail-bounded heavy metal concentrations. The other examined factors examined in this study including age, BMI, educational level, and duration of working in cafés had no significant relationship with the concentrations of toenailbounded heavy metals.

There was a significant positive relationship ( $P_{\text {value- }}$ $<0.01$ ) between amounts of toenail-bounded heavy metals and type of tobacco. For further investigation,

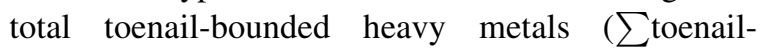
bounded heavy metal) were compared in those working in cafés with fruit-flavored and traditional tobacco cafés and results are depicted in Fig. 2. As shown, total amounts of heavy metals in the toenail samples of those, who worked in cafés with fruit-flavored and traditional tobacco cafés, were $68.88 \pm 20.49$ and $39.57 \pm 6.34 \mu \mathrm{g} / \mathrm{g}$, respectively. For the customers, the participants' metal contents were $32.71 \pm 7.12$ and $20.52 \pm 3.93 \mu \mathrm{g} / \mathrm{g}$ by consuming fruit-flavored and traditional tobacco, respectively. Fruit-flavored tobacco contains high levels of organic chemicals, aroma, essential oils, and flavoring additives that are added to this type of tobacco during its manufacturing process (Farley et al. 2018). Therefore, this type of tobacco releases higher amounts of various air pollutants into the indoor air of cafés during burning, and consequently, those who work in such cafés, are more exposed to higher concentrations of contaminants (Rostami et al. 2019; Heydari et al. 2019). In this regard, high concentrations of toenail-bounded heavy metals in workers of fruit-flavored tobacco cafés can be due to the above-mentioned reason. In line with 


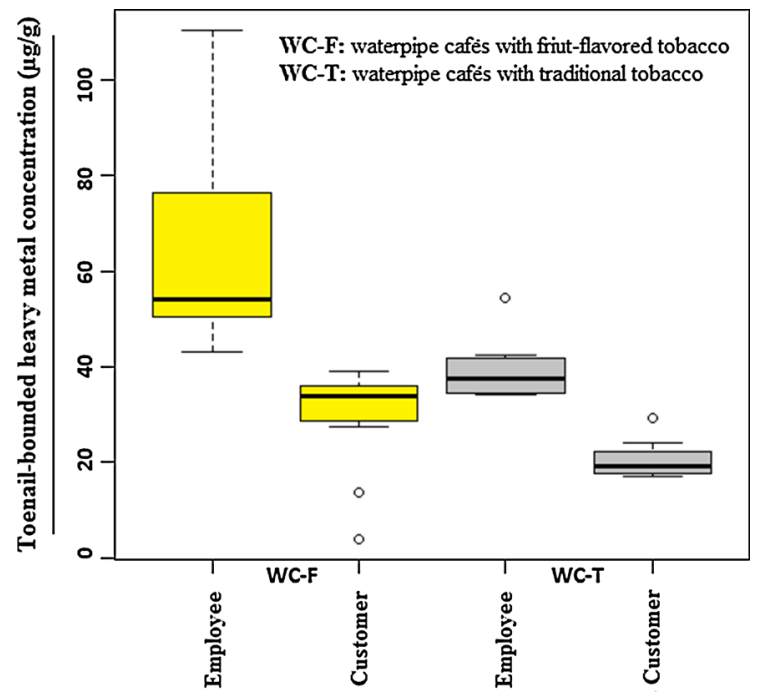

Fig. 2 Box plot of levels of toenail-bounded heavy metals $(\mu \mathrm{g} /$ g) stratified by "tobacco type" (Employee: workers in waterpipe/cigarette cafés, Customers: customers in waterpipe/cigarette cafés, WC-F: waterpipe cafés with fruit-flavored tobacco and WC-T: waterpipe cafés with traditional tobacco)

these statements, Naddafi et al. (2019) in their study reported higher values of PAHs, particles, formaldehyde, and acetaldehyde in the air inside the fruitflavored tobacco cafés compared to the traditional tobacco cafés. Masjedi et al. (2019a) have also observed high values of gaseous pollutants such as $\mathrm{CO}$, formaldehyde and nicotine inside the cafés that supplied the fruit-flavored tobacco. Because of the sweet and tasty flavor of this type of tobacco, and its slow burning, fruit-flavored tobacco is known as a fun activity for young people who tend to spend much time in these cafés. Therefore, they are exposed to higher concentrations of pollutants (Naddafi et al. 2019).

There was a positive and significant relationship $\left(P_{\text {value }}<0.05\right)$ between concentrations of toenailbounded heavy metals with number of services per day and café's distance from traffic. Accordingly, number of services per day in cafés refers to number of "active waterpipe /cigarette heads" per day. Increasing number of "active waterpipe /cigarette heads" within cafés subsequently raises amounts of tobacco smoke in the indoor air, thereby producing higher concentrations of contaminants and more exposing the cafés workers and customers (Rostami et al. 2019; Heydari et al. 2019; Masjedi et al. 2019a). The traffic density of areas, where the study population lived, also 
was another factor affecting the measured toenailbounded metals levels (Table 3 ). It was consistent with the findings of previous studies that reported the higher exposure to air contaminants for people living near the busy roads compared to those living in a far distance from roads (Jafari et al. 2018; Phuc and Kim Oanh 2018).

A significant but negative relationship was also observed between the use of personal protective equipment (N95 mask, etc.) and toenail-bounded metal concentrations $\left(P_{\text {value }}<0.05\right)$. The finding can be attributed to the efficiencies of filters and mask on preventing the entry of solid and liquid suspended particulates. Since most of the released heavy metals in the air are in the particulate phase (Ndilila et al. 2014), the use of appropriate masks and filters can reduce the individual exposure to these particulate pollutants as well as reducing their amounts (heavy metals) in toenail samples. Previous investigators have also demonstrated that demographic and lifestyle factors are important pathways and contributors for metals exposure (Ndilila et al. 2014). Age, resident period (exposure period), previous occupational exposure and passive cigarette smoke exposures have all been shown to be important factors influencing metals exposure (Hogervorst et al. 2007).

\section{Metal exposures and oxidative stress}

The level of 8-hydroxy-2'-deoxyguanosine (8-OHdG, as a biomarker of oxidative stress) was measured in the urine samples collected from the waterpipe/cigarette cafés workers and customers, and the control groups, to evaluate the relationship between heavy metal exposure and oxidative stress in them. Thereafter, the Pearson correlations were used to evaluate the association between the values of toenail-bounded heavy metals and the concentration of $8-\mathrm{OHdG}$, as presented in Table 4. As shown, the concentration of $8-\mathrm{OHdG}$ was positively and significantly related to the concentrations of all toenail-metals among waterpipe/cigarette cafés workers and customers; however, the relationship was only for the concentrations of 8-OHdG and zinc in the control groups $\left(\mathrm{CG}_{-} 1\right.$ and CG_2). The findings suggested that the exposure to heavy metals was associated with oxidative degradation of DNA in the waterpipe/cigarette cafés workers and customers. Among all these metals, arsenic, cadmium, lead, and chromium had high correlation

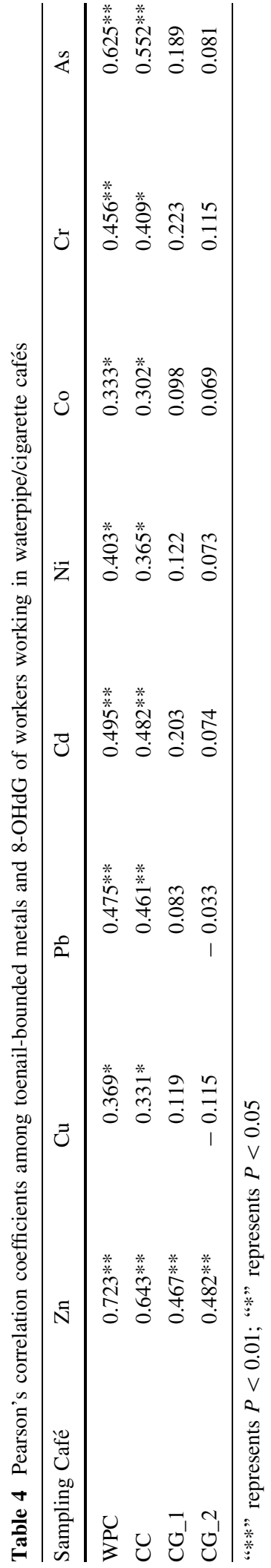


coefficients measured as $0.625,0.495,0.475$ and 0.456 in waterpipe cafés and $0.552,0.482,0.461$ and 0.409 in cigarette cafés, respectively. To the best of our knowledge, $\mathrm{As}, \mathrm{Cd}, \mathrm{Pb}$, and $\mathrm{Cr}$ are known as toxic metals. The results of numerous epidemiological studies indicated that the exposure to the abovementioned metals is associated with the increased oxidative degradation of DNA in humans (Wong et al. 2005; Wei et al. 2009; Ni et al. 2014). Findings of the present study are consistent with the results reported by Zhang et al. (2019), who studied the exposure to heavy metals in the individuals working in the electronic waste recycling facilities. An interesting finding of the present study was a positive and significant relationship found between the concentrations of 8-OHdG and zinc even in the control groups. Several in vivo and in vitro studies have indicated that essential elements, such as zinc, copper, and cobalt can also cause redox cycling reactions and also are capable of producing active species and free radicals such as nitric oxide and superoxide anion radical in biological systems like human body, so they have a high potential for health risks (Speisky et al. 2009; Galanis et al. 2009; Jomova and Valko 2011; Liochev and Fridovich 2000). Despite the fact that the mechanism of the increased oxidative stress by essential elements needs a more accurate examination by performing other studies, a significant positive association found between toenail-bounded metals and oxidative stress biomarkers in waterpipe/cigarette cafés workers and customers indicated that they are exposed to greater health risks.

\section{Limitations and ideas for future researches}

The current study had a series of limitations that should be widely taken into account in using the findings for smoking cafés elsewhere in the world. The first limitation of this research was a low sample size; therefore, further studies should be carried out in a more comprehensive way with greater sample sizes. Moreover, the investigated contaminants in this study were limited only to heavy metals, while some other dangerous and toxic pollutants in tobacco smoke such as propylene oxide, benzene, toluene, ethylbenzene and xylene (BTEX), acrolein, acrylonitrile, polycyclic aromatic hydrocarbons (PAHs), 1,3-butadiene, ethylene oxide, nitrosamines, and their metabolites were not investigated in the biological samples of the exposed people in this study due to a lack of sampling and analysis equipment as well as lack of research funding. So, they can be taken into account as attractive ideas for future studies. In addition, waterpipe and cigarettes smoke are not the only sources of exposure to heavy metals in such cafés, and some other sources of heavy metals that enter the body such as drinking water and foods can also be considered. Therefore, besides toenails samples, there is a need for performing a more comprehensive and detailed study on these metals in drinking water samples, foodstuffs in such cafés, and so on. Furthermore, a closer examination of the mechanism of oxidative stress increase caused by heavy metals in tobacco smoke requires more detailed evaluations.

\section{Conclusion}

Despite the fact that the current work was the first work conducted on levels of toenail-bounded heavy metals in waterpipe/cigarette cafés workers and customers have some limitations, it also had valuable results, indicating that their exposure to heavy metals was significantly high. Findings of the present study have also indicated that there was a significant difference in terms of the toenail-bounded metals between the exposed and the control groups. Moreover, the results confirmed that working in waterpipe/cigarette cafés is a potential occupational hazard in terms of exposure to heavy metals. The present study also indicated that "type of tobacco" could be used as a predictor for toenail-bounded heavy metal concentrations, in a way that those, who worked in cafés serving fruit-flavored tobacco or were customers, showed higher levels of heavy metals in their toenail samples. Furthermore, number of services per day, distance from traffic, and use of personal protective equipment were three predictors of concentrations of toenail-bounded heavy metals in waterpipe/cigarette cafés workers and customers. In addition, the results of the present study suggest that the concentrations of toenail-bounded heavy metals in the studied participants were significantly and positively correlated with the urinary concentration of 8-OHdG, which is a biomarker for degradation of DNA oxidative stress. Finally, it can be concluded that waterpipe/cigarette cafés workers are at a high health risk for oxidative degradation of DNA. Therefore, 
effective protective strategies are needed to reduce their exposure and amounts of various chemical pollutants in the air inside the cafés.

Acknowledgements The research reported in this manuscript has been funded through the Tobacco Control Research Center (TCRC) (Grant No. TCRC/IATA1396-10) and Systems Environmental Health and Energy Research Center of Bushehr University of Medical Sciences (Grant No. 1421). This work has received approval for research ethics from Bushehr Province University of Medical Sciences and a proof/ certificate of approval is available as "Research ethics approval" in the list of uploaded file.

\section{References}

Ab Razak, N. H., Praveena, S. M., \& Hashim, Z. (2015). Toenail as a biomarker of heavy metal exposure via drinking water: A systematic review. Reviews on Environmental Health, $30,1-7$.

Akl, E. A., Gaddam, S., Gunukula, S. K., Honeine, R., Jaoude, P. A., \& Irani, J. (2010). The effects of waterpipe tobacco smoking on health outcomes: A systematic review. International Journal of Epidemiology, 39, 834-857.

Al-Saleh, I. (2020). Reference values for heavy metals in the urine and blood of Saudi women derived from two human biomonitoring studies. International Journal of Hygiene and Environmental Health, 225, 113473.

Arora, M., Weuve, J., Schwartz, J., \& Wright, R. O. (2009). Association of environmental cadmium exposure with periodontal disease in US adults. Environmental Health Perspectives, 117, 739.

Asante, K. A., Agusa, T., Biney, C. A., Agyekum, W. A., Bello, M., Otsuka, M., et al. (2012). Multi-trace element levels and arsenic speciation in urine of e-waste recycling workers from Agbogbloshie, Accra in Ghana. Science of The Total Environment, 424, 63-73.

Asfar, T., Ward, K. D., Eissenberg, T., \& Maziak, W. (2005). Comparison of patterns of use, beliefs, and attitudes related to waterpipe between beginning and established smokers. BMC Public Health, 5, 19.

Bamai, Y. A., Bastiaensen, M., Araki, A., Goudarzi, H., Konno, S., Ito, S., et al. (2019). Multiple exposures to organophosphate flame retardants alter urinary oxidative stress biomarkers among children: The Hokkaido Study. Environment International, 131, 105003.

Camargo, J., Pumarega, J. A., Alguacil, J., Sanz-Gallén, P., Gasull, M., Delclos, G. L., et al. (2019). Toenail concentrations of trace elements and occupational history in pancreatic cancer. Environment International, 127, 216-225.

Coelho, P., Costa, S., Silva, S., Walter, A., Ranville, J., Sousa, A. C., et al. (2012). Metal (loid) levels in biological matrices from human populations exposed to mining contamination-Panasqueira Mine (Portugal). Journal of Toxicology and Environmental Health, Part A, 75, 893-908.
Drago, G., Perrino, C., Canepari, S., Ruggieri, S., L'Abbate, L., Longo, V., et al. (2018). Relationship between domestic smoking and metals and rare earth elements concentration in indoor PM2.5. Environmental Research, 165, 71-80.

Farley, S. M., Schroth, K. R., Grimshaw, V., Luo, W., Degagne, J. L., Tierney, P. A., et al. (2018). Flavour chemicals in a sample of non-cigarette tobacco products without explicit flavour names sold in New York City in 2015. Tobacco Control, 27, 170-176.

Fromme, H., Dietrich, S., Heitmann, D., Dressel, H., Diemer, J., Schulz, T., et al. (2009). Indoor air contamination during a waterpipe (narghile) smoking session. Food and Chemical Toxicology, 47, 1636-1641.

Galanis, A., Karapetsas, A., \& Sandaltzopoulos, R. (2009). Metal-induced carcinogenesis, oxidative stress and hypoxia signalling. Mutation Research/Genetic Toxicology and Environmental Mutagenesis, 674, 31-35.

Ghezel-Ahmadi, D., Engel, A., Weidemann, J., Budnik, L. T., Baur, X., Frick, U., et al. (2010). Heavy metal exposure in patients suffering from electromagnetic hypersensitivity. Science of the Total Environment, 408, 774-778.

Grashow, R., Zhang, J., Fang, S. C., Weisskopf, M. G., Christiani, D. C., \& Cavallari, J. M. (2014). Toenail metal concentration as a biomarker of occupational welding fume exposure. Journal of Occupational and Environmental Hygiene, 11, 397-405.

Gregg, E. O., Minet, E., \& Mcewan, M. (2013). Urinary biomarkers of smokers' exposure to tobacco smoke constituents in tobacco products assessment: A fit for purpose approach. Biomarkers, 18, 467-486.

Gurung, G., Bradley, J., \& Delgado-Saborit, J. M. (2016). Effects of shisha smoking on carbon monoxide and PM2. 5 concentrations in the indoor and outdoor microenvironment of shisha premises. Science of the Total Environment, 548, 340-346.

Habibollahi, M. H., Karimyan, K., Arfaeinia, H., Mirzaei, N., Safari, Y., Akramipour, R., et al. (2019). Extraction and determination of heavy metals in soil and vegetables irrigated with treated municipal wastewater using new mode of dispersive liquid-liquid microextraction based on the solidified deep eutectic solvent followed by GFAAS. Journal of the Science of Food and Agriculture, 99, $656-665$.

Haghnazari, L., Mirzaei, N., Arfaeinia, H., Karimyan, K., Sharafi, H., \& Fattahi, N. (2018). Speciation of As (III)/As (V) and total inorganic arsenic in biological fluids using new mode of liquid-phase microextraction and electrothermal atomic absorption spectrometry. Biological Trace Element Research, 183, 173-181.

Heydari, G., Taghizdeh, F., Fazlzadeh, M., Jafari, A. J., Asadgol, Z., Mehrizi, E. A., et al. (2019). Levels and health risk assessments of particulate matters (PM 2.5 and PM 10) in indoor/outdoor air of waterpipe cafés in Tehran, Iran. Environmental Science and Pollution Research, 26, 7205-7215.

Hinwood, A. L., Sim, M. R., Jolley, D., De Klerk, N., Bastone, E. B., Gerostamoulos, J., \& Drummer, O. H. (2003). Hair and toenail arsenic concentrations of residents living in areas with high environmental arsenic concentrations. Environmental Health Perspectives, 111, 187-193. 
Hogervorst, J., Plusquin, M., Vangronsveld, J., Nawrot, T., Cuypers, A., Van Hecke, E., et al. (2007). House dust as possible route of environmental exposure to cadmium and lead in the adult general population. Environmental Research, 103, 30-37.

Hordinsky, M. K., Sawaya, M. E., \& Scher, R. K. (2000). Atlas of hair and nails. London: Churchill Livingstone.

Jafari, A. J., Kermani, M., Kalantary, R. R., \& Arfaeinia, H. (2018). The effect of traffic on levels, distribution and chemical partitioning of harmful metals in the street dust and surface soil from urban areas of Tehran, Iran. Environmental Earth Sciences, 77, 38.

Jomova, K., \& Valko, M. (2011). Advances in metal-induced oxidative stress and human disease. Toxicology, 283, $65-87$.

Karatela, S., Ward, N. I., Zeng, I. S., \& Paterson, J. (2018). Status and interrelationship of toenail elements in Pacific children. Journal of Trace Elements in Medicine and Biology, 46, 10-16.

Kim, Y. J., Kim, Y. K., \& Kho, H. S. (2010). Effects of smoking on trace metal levels in saliva. Oral Diseases, 16, 823-830.

Laohaudomchok, W., Lin, X., Herrick, R. F., Fang, S. C., Cavallari, J. M., Christiani, D. C., \& Weisskopf, M. G. (2011). Toenail, blood and urine as biomarkers of manganese exposure. Journal of Occupational and Environmental Medicine/American College of Occupational and Environmental Medicine, 53, 506.

Li, Y., Zou, X., Lv, J., Yang, L., Li, H., \& Wang, W. (2012). Trace elements in fingernails of healthy Chinese centenarians. Biological Trace Element Research, 145, $158-165$.

Lim, J. T., Tan, Y. Q., Valeri, L., Lee, J., Geok, P. P., Chia, S. E., et al. (2019). Association between serum heavy metals and prostate cancer risk-A multiple metal analysis. Environment International, 132, 105109.

Liochev, S. I., \& Fridovich, I. (2000). Copper-and zinc-containing superoxide dismutase can act as a superoxide reductase and a superoxide oxidase. Journal of Biological Chemistry, 275, 38482-38485.

Liu, Y., Yuan, Y., Xiao, Y., Li, Y., Yu, Y., Mo, T., et al. (2020). Associations of plasma metal concentrations with the decline in kidney function: A longitudinal study of Chinese adults. Ecotoxicology and Environmental Safety, 189, 110006.

Lugon-Moulin, N., Zhang, M., Gadani, F., Rossi, L., Koller, D., Krauss, M., \& Wagner, G. (2004). Critical review of the science and options for reducing cadmium in tobacco (Nicotiana tabacum L.) and other plants. Advances in Agronomy, 83, 112-181.

Masjedi, M. R., Taghizadeh, F., Hamzehali, S., Ghaffari, S., Fazlzadeh, M., Jafari, A. J., et al. (2019a). Air pollutants associated with smoking in indoor/outdoor of waterpipe cafés in Tehran, Iran: Concentrations, affecting factors and health risk assessment. Scientific Reports, 9, 3110.

Masjedi, M. R., Taghizadeh, F., Hamzehali, S., Ghaffari, S., Fazlzadeh, M., Jafari, A. J., et al. (2019b). Air pollutants associated with smoking in indoor/outdoor of waterpipe cafés in Tehran, Iran: Concentrations, affecting factors and health risk assessment. Scientific Reports, 9, 1-11.
Mehra, R., \& Juneja, M. (2005). Fingernails as biological indices of metal exposure. Journal of Biosciences, 30, 253-257.

Naddafi, K., Nabizadeh, R., Rostami, R., Ghaffari, H. R., \& Fazlzadeh, M. (2019). Formaldehyde and acetaldehyde in the indoor air of waterpipe cafés: Measuring exposures and assessing health effects. Building and Environment, 165, 106392.

Ndilila, W., Callan, A. C., Mcgregor, L. A., Kalin, R. M., \& Hinwood, A. L. (2014). Environmental and toenail metals concentrations in copper mining and non mining communities in Zambia. International Journal of Hygiene and Environmental Health, 217, 62-69.

Ni, W., Huang, Y., Wang, X., Zhang, J., \& Wu, K. (2014). Associations of neonatal lead, cadmium, chromium and nickel co-exposure with DNA oxidative damage in an electronic waste recycling town. Science of the Total Environment, 472, 354-362.

Omari, M., Kibet, J., Cherutoi, J., Bosire, J., \& Rono, N. (2015). Heavy metal content in mainstream cigarette smoke of common cigarettes sold in Kenya, and their toxicological consequences. International Research Journal of Environmental Sciences, 4, 75-79.

Pääkkö, P., Kokkonen, P., Anttila, S., \& Kalliomäki, P.-L. (1989). Cadmium and chromium as markers of smoking in human lung tissue. Environmental Research, 49, 197-207.

Pappas, R., Polzin, G., Watson, C., \& Ashley, D. (2007). Cadmium, lead, and thallium in smoke particulate from counterfeit cigarettes compared to authentic US brands. Food and Chemical Toxicology, 45, 202-209.

Phuc, N. H., \& Kim Oanh, N. T. (2018). Determining factors for levels of volatile organic compounds measured in different microenvironments of a heavy traffic urban area. Science of The Total Environment, 627, 290-303.

Rocha, G., Steinbach, C., Munhoz, J., Madia, M., Faria, J., Hoeltgebaum, D., et al. (2016). Trace metal levels in serum and urine of a population in southern Brazil. Journal of Trace Elements in Medicine and Biology, 35, 61-65.

Rodgman, A., \& Perfetti, T. A. (2016). The chemical components of tobacco and tobacco smoke. Boca Raton: CRC Press.

Rostami, R., Zarei, A., Saranjam, B., Ghaffari, H. R., Hazrati, S., Poureshg, Y., \& Fazlzadeh, M. (2019). Exposure and risk assessment of PAHs in indoor air of waterpipe cafés in Ardebil, Iran. Building and Environment, 155, 47-57.

Samanta, G., Sharma, R., Roychowdhury, T., \& Chakraborti, D. (2004). Arsenic and other elements in hair, nails, and skinscales of arsenic victims in West Bengal, India. Science of the Total Environment, 326, 33-47.

Schwartz, G. G., Il'Yasova, D., \& Ivanova, A. (2003). Urinary cadmium, impaired fasting glucose, and diabetes in the NHANES III. Diabetes Care, 26, 468-470.

Schwartz, G. G., \& Reis, I. M. (2000). Is cadmium a cause of human pancreatic cancer? Cancer Epidemiology and Prevention Biomarkers, 9, 139-145.

Sebiawu, G. E., Mensah, N. J., \& Ayiah-Mensah, F. (2014). Analysis of heavy metals content of tobacco and cigarettes sold in Wa Municipality of Upper West Region, Ghana. Chemical and Process Engineering Research, 25, 24-33.

Slotnick, M. J., Nriagu, J. O., Johnson, M. M., Linder, A. M., Savoie, K. L., Jamil, H. J., \& Hammad, A. S. (2005). 
Profiles of trace elements in toenails of Arab-Americans in the Detroit area, Michigan. Biological Trace Element Research, 107, 113-126.

Speisky, H., Gómez, M., Burgos-Bravo, F., López-Alarcón, C., Jullian, C., Olea-Azar, C., \& Aliaga, M. E. (2009). Generation of superoxide radicals by copper-glutathione complexes: Redox-consequences associated with their interaction with reduced glutathione. Bioorganic \& Medicinal Chemistry, 17, 1803-1810.

Suwazono, Y., Kido, T., Nakagawa, H., Nishijo, M., Honda, R., Kobayashi, E., et al. (2009). Biological half-life of cadmium in the urine of inhabitants after cessation of cadmium exposure. Biomarkers, 14, 77-81.

Swami, K., Judd, C. D., \& Orsini, J. (2009). Trace metals analysis of legal and counterfeit cigarette tobacco samples using inductively coupled plasma mass spectrometry and cold vapor atomic absorption spectrometry. Spectroscopy Letters, 42, 479-490.

Verma, S., Yadav, S., \& Singh, I. (2010). Trace metal concentration in different Indian tobacco products and related health implications. Food and Chemical Toxicology, 48, 2291-2297.

Wei, Y., Han, I.-K., Shao, M., Hu, M., Zhang, J., \& Tang, X. (2009). PM2. 5 constituents and oxidative DNA damage in humans. Environmental Science \& Technology, 43, 4757-4762.

WHO. Media centre. Retrieved October 2017, https://www. who.int/mediacentre/factsheets/fs339/en/. Updated 2017.

Wickre, J. B., Folt, C. L., Sturup, S., \& Karagas, M. R. (2004). Environmental exposure and fingernail analysis of arsenic and mercury in children and adults in a Nicaraguan gold mining community. Archives of Environmental Health: An International Journal, 59, 400-409.
Wilhelm, M., Lombeck, I., \& Ohnesorge, F. K. (1994). Cadmium, copper, lead and zinc concentrations in hair and toenails of young children and family members: A followup study. Science of the Total Environment, 141, 275-280.

Wong, R.-H., Kuo, C.-Y., Hsu, M.-L., Wang, T.-Y., Chang, P.I., Wu, T.-H., \& Huang, S. (2005). Increased levels of 8-hydroxy-2'-deoxyguanosine attributable to carcinogenic metal exposure among schoolchildren. Environmental Health Perspectives, 113, 1386-1390.

Wongsasuluk, P., Chotpantarat, S., Siriwong, W., \& Robson, M. (2018). Using hair and fingernails in binary logistic regression for bio-monitoring of heavy metals/metalloid in groundwater in intensively agricultural areas, Thailand. Environmental Research, 162, 106-118.

Yang, K., Xun, P., Carnethon, M., Carson, A. P., Lu, L., Zhu, J., $\& \mathrm{He}, \mathrm{K}$. (2019). Low to moderate toenail arsenic levels in young adulthood and incidence of diabetes later in life: Findings from the CARDIA Trace Element study. Environmental Research, 171, 321-327.

Zhang, T., Ruan, J., Zhang, B., Lu, S., Gao, C., Huang, L., et al. (2019). Heavy metals in human urine, foods and drinking water from an e-waste dismantling area: Identification of exposure sources and metal-induced health risk. Ecotoxicology and Environmental Safety, 169, 707-713.

Zhao, L., Li, Y., Ren, W., Huang, Y., Wang, X., Fu, Z., et al. (2020). Pesticide residues in soils planted with Panax notoginseng in south China, and their relationships in Panax notoginseng and soil. Ecotoxicology and Environmental Safety, 201, 110783.

Publisher's Note Springer Nature remains neutral with regard to jurisdictional claims in published maps and institutional affiliations. 